\title{
Assimetria da informação e a gestão do conhecimento estratégico em processos regulatórios ${ }^{\prime}$
}

\author{
Information asymmetry and strategic knowledge management in \\ regulatory processes
}

Shirley Guimarães PIMENTA²

\section{RESUMO}

presente artigo apresenta os resultados de pesquisa que teve por objetivo avaliar os possíveis impactos da assimetria da informação na atuação de estrategistas e decisores no procedimento de revisão tarifária das distribuidoras de energia elétrica adotado pela Agência Nacional de Energia Elétrica (ANEEL). $O$ estudo utilizou o modelo da Gestão do Conhecimento Estratégico. Inicialmente, a situação problema é contextualizada por meio da apresentação de aspectos da organização da ANEEL - competências legais, modelo decisório, estrutura organizacional e outros fatores relevantes -, de modo a favorecer a compreensão do ambiente dentro do qual a questão foi observada. $\bigcirc$ estudo voltou sua atenção para a atuação de estrategistas e decisores - formuladores da proposta de revisão e Diretoria Colegiada - no procedimento de revisão tarifária, com coleta de dados por meio da utilização de questionários e entrevistas. Os resultados apontaram inadequações e inconsistências em alguns dos mecanismos adotados, os quais têm por finalidade minimizar a assimetria de informação. Observou-se também que a entidade não tem considerado alguns fatores sistêmicos da Gestão do Conhecimento Estratégico, a o passo que outros estão desenvolvidos. Na conclusão são apontadas algumas sugestões com vistas à melhoria do procedimento, a exemplo da indicação de desenvolvimento e manutenção de expertise.

Palavras-chave: assimetria da informação; regulação, gestão do conhecimento estratégico; agências reguladoras.

\footnotetext{
ABSTRACT

This paper presents results of research that aims at assessing the possible impacts of the asymmetry of information in the performance of strategists and decision-makers in tax revision procedure of electric energy adopted by the Agência Nacional de Energia Elétrica (ANEEL). The study conducted from the perspective of the Strategic Knowledge Management. Analysis focus on the design of some aspects of the organizational frame and it aims at better understanding the environment within which the state-problem is experimented. It was made description of the

As conclusões expressas neste trabalho acadêmico são de responsabilidade dos autores, não necessariamente coincidindo com o ponto de vista dos servidores e dirigentes da entidade objeto da pesquisa.

2 Mestre em Ciência da Informação, Universidade de Brasília, UNB, Brasil. Analista Administrativo e Coordenadora da Coordenação de Atividades de Arrecadação, Agência Nacional de Energia Elétrica. SGAN Q, 603, Módulos I e J, Asa Norte, 70830-030, Brasília, DF, Brasil. <shirleygpimenta@yahoo.com.br>.

Recebido em 13/2/2009 e aceito para publicação em 17/6/2009.
}

TransInformação, Campinas, 21 (2): 99-116, maio/ago., 2009 
legal competences, decision- making model, organizational structure and other relevant factors in relation to procedure for revising the subject. Methodology comprises questionnaires applied to people involved to formulate and propose revision and to the Collegiate Directors - strategists and decision-makers. Results pointed out inadequacies and inconsistencies in some methods adopted to minimize the asymmetry of information. It was observed that the Agency has not considered some of the systemic factors of Strategic Knowledge Management, while other factors are fairly developed. It was noted that there is the need for development and maintenance of expertise. It is proposed implementation of actions in order to develop and maintain expertise as a means to combat the asymmetry of information.

Keywords: asymmetry of information; regulation; strategic knowledge management; regulatory agency.

\section{INTRODUÇÃO}

A economia contemporânea é influenciada pela informação, de tal forma que o Nobel em Economia em 2001, Joseph E. Stiglitz a chamou de economia da informação (Stiglitz; Walsh, 2003). Alguns teóricos acrescentam a informação no rol dos recursos (Herscovici, 2001 ; Tarapanoff, 2002), o que significa que ela tem sido considerada como um fator gerador de riquezas. Lembrando que para a clássica teoria econômica, recursos geradores de riqueza são: terra, mão-de-obra, reservas naturais, capital e tecnologia (Rosseti, 1987; Vasconcellos; Garcia 1998), permitese inferir, nesse sentido, que, como os demais recursos, a informação pode ser escassa, de elevado custo de obtenção e demandar modelos adequados para ser gerenciada.

No contexto da Ciência da Informação (Cl), Le Coadic (2004) afirma que o objeto e problemas fundamentais de pesquisa dessa ciência são pertinentes ao estudo das propriedades gerais (natureza, gênese e efeitos), dos processos e sistemas de construção, comunicação e uso da informação. Para Brookes (1980) a Cl deve ocupar-se do mundo do conhecimento objetivo, traduzidos nos produtos da mente humana como registrado nas linguagens, nas artes, nas ciências, nas tecnologias. E por que não acrescentar, nas formas de organização criadas e integradas pelos seres humanos?

Desse modo, acredita-se que a $\mathrm{Cl}$ deva acompanhar os assuntos do mundo contemporâneo, palco de inúmeras crises, evoluções, inovações, como é próprio de todo sistema aberto. Cabe-lhe dar sua contribuição na solução de problemas e novas propostas, a partir da avaliação de assuntos cujo cerne seja a informação.
Paralelamente, o presente estudo contribui com a $\mathrm{Cl}$ ao apresentar resultados de pesquisa em que a informação foi avaliada sob a perspectiva de ser um "bem" escasso, falho em seus requisitos fundamentais de boa informação, o que afeta a sua função de redutor de incertezas e de erros na formulação de estratégias e na tomada de decisão. O conceito de assimetria de informação, com o qual se lida neste trabalho, é um conceito oriundo e explorado pela ciência da Economia. No entanto desconhece-se a avaliação dele e de seu impacto sobre os usuários de informação no âmbito $\mathrm{da} \mathrm{Cl}$.

Uma vez justificada a relevância do estudo de temas da atualidade no âmbito da $\mathrm{Cl}$, compete situar a atenção ao contexto brasileiro da década de 1990, período em que o Estado Brasileiro passou por mudanças (Pereira, 1995), não ficando incólume às transformações sofridas em outras partes do mundo na mesma época. O Estado foi submetido a discussões e recriações, que culminaram, por exemplo, na reforma administrativa, durante a qual surgiram as agências reguladoras de mercados, como, por exemplo, a Agência Nacional de Energia Elétrica (Brasil, 1996), a Agência Nacional de Telecomunicações (Brasil, 1997a), a Agência Nacional do Petróleo (Brasil, 1997b) e a Agência Nacional de Vigilância Sanitária (Brasil, 1999).

No Brasil, as agências reguladoras criadas até o ano de 2006 foram constituídas na forma de pessoa jurídica de direito público, autarquias em regime especial, portadoras de autonomia administrativa, independentes financeiramente e não subordinadas hierarquicamente ao órgão ao qual se vinculam (Pimenta, 2007). De modo geral, as agências reguladoras têm por função regular o mercado por meio da edição de normas, além de fiscalizar e mediar conflitos entre agentes. E, na realização dessa tarefa, revela-se $O$ aspecto dependente de informação na 
função reguladora do Estado. A regulação se faz, em grande parte, pelo uso de informação acerca não somente do mercado e dos agentes regulados como também das situações impactantes sobre eles.

Contudo a relação entre regulador e o regulado - ou seja, agente regulador/agência reguladora e agente regulado/agente de mercado - é marcada pelo acesso assimétrico à informação. Esse fato caracteriza um dos principais problemas da regulação: a assimetria de informação. Tal situação ocorre quando o agente regulado, detentor da informação, pode sonegá-la, manipulá-la, administrá-la em benefício próprio em detrimento da ação do ente que dela depende para tomar decisões de regulação sobre o mercado (Genoud, 2003; Piccinini; Pires, 1998)

Nesse contexto, com o presente artigo tem-se a intenção de apresentar a avaliação de como o problema da assimetria de informação tem sido percebido e tem impactado a atuação dos formuladores da proposta de revisão tarifária e da Diretoria Colegiada no âmbito da Agência Nacional de Energia Elétrica (ANEEL), quando da realização da revisão tarifária das distribuidoras de energia elétrica.

A questão problema levantada foi: quais os possíveis impactos da assimetria da informação na atuação dos estrategistas e decisores no procedimento de revisão tarifária periódica das distribuidoras de energia elétrica adotado pela ANEEL?

O objetivo geral que orientou a realização do estudo foi o de avaliar, sob a perspectiva da Gestão do Conhecimento Estratégico (GCE), quais os possíveis impactos da assimetria de informação na atuação de estrategistas e decisores no procedimento de revisão tarifária periódica das distribuidoras de energia elétrica adotado pela ANEEL. Os objetivos específicos e as hipóteses formuladas estão descritos na Tabela 1:

Tabela 1. Objetivos específicos e hipóteses.

\begin{tabular}{|c|c|}
\hline Objetivo específico & Hipótese \\
\hline $\begin{array}{l}\text { Avaliar se há inconsistências e inadequações na } \\
\text { metodologia de revisão tarifária periódica das } \\
\text { distribuidoras de energia elétrica adotada pela ANEEL, } \\
\text { de forma que contribuam para aumentar os efeitos da } \\
\text { assimetria da informação nesse processo regulatório. }\end{array}$ & $\begin{array}{l}\text { Há inconsistências e inadequações na forma como é } \\
\text { realizado o procedimento de revisão tarifária das } \\
\text { distribuidoras de energia elétrica adotado pela ANEEL, } \\
\text { o que contribui para aumentar os efeitos da assimetria } \\
\text { da informação nesse processo regulatório }\end{array}$ \\
\hline $\begin{array}{l}\text { Avaliar em que medida a assimetria de informação é } \\
\text { percebida pelos estrategistas e decisores no } \\
\text { procedimento de revisão tarifária periódica das } \\
\text { distribuidoras de energia elétrica adotado pela ANEEL. }\end{array}$ & $\begin{array}{l}\text { Os estrategistas e os decisores não consideram que } \\
\text { haja assimetria de informação nos procedimentos de } \\
\text { revisão tarifária, por acreditarem que o problema foi } \\
\text { solucionado pela metodologia adotada e pelos } \\
\text { mecanismos utilizados. }\end{array}$ \\
\hline $\begin{array}{l}\text { Avaliar em que medida a ANEEL considera, no } \\
\text { procedimento de revisão tarifária periódica das } \\
\text { distribuidoras de energia elétrica, a influência, sobre } \\
\text { os estrategistas e decisores, dos fatores sistêmicos da } \\
\text { GCE. }\end{array}$ & $\begin{array}{l}\text { O procedimento de revisão tarifária das distribuidoras } \\
\text { de energia elétrica adotado pela ANEEL não considera } \\
\text { a influência dos fatores sistêmicos da GCE relacionadas } \\
\text { à condição de estrategista e decisor, novato ou } \\
\text { experiente, o que pode conduzir a formulação e a } \\
\text { tomada de decisão inadequadas. }\end{array}$ \\
\hline $\begin{array}{l}\text { Propor ajustes nos processos de formulação de proposta } \\
\text { tarifária e tomada de decisão com vistas a melhores } \\
\text { resultados nos procedimentos de revisão tarifária } \\
\text { periódica. }\end{array}$ & $\begin{array}{l}\text { O procedimento de revisão tarifária das distribuidoras } \\
\text { de energia elétrica adotado pela ANEEL tende a ser } \\
\text { aprimorado, se considerados os fatores sistêmicos da } \\
\text { GCE. }\end{array}$ \\
\hline
\end{tabular}


No procedimento de revisão tarifária das distribuidoras de energia elétrica, dos quais resultam as tarifas a serem pagas pelos serviços, a ANEEL adota a metodologia da regulação por incentivos, e faz uso dos mecanismos abaixo assinalados para minimizar a assimetria de informação:

- empresa de referência;

- conselho de consumidores;

- empresas credenciadas; e

- consultas e audiências públicas.

Cabe ainda ressaltar que o estudo o qual deu origem ao presente artigo, além de considerar os instrumentos acima, utilizou o modelo de Gestão do Conhecimento Estratégico na definição da perspectiva sob a qual a situação-problema foi examinada.

\section{CONTEXTO INSTITUCIONAL DA SITUAÇÃO- PROBLEMA - A ANEEL}

A ANEEL é entidade brasileira da administração pública indireta federal, com a tarefa de regular e fiscalizar a geração, transmissão, distribuição e comercialização de energia elétrica. Tem a sua atuação balizada na observância das políticas e diretrizes para o setor elétrico emanadas do governo federal.

Foi instituída pela Lei 9.427, de 26 de dezembro de 1996, na forma de autarquia em regime especial, o que the confere autonomia administrativa, independência financeira e não subordinação hierárquica em relação ao órgão ao qual está vinculada, o Ministério de Minas e Energia.

A ANEEL foi criada para proporcionar um ambiente que fosse percebido pelos agentes do mercado de energia elétrica como atrativo para investimentos, garantindo o atendimento a uma demanda crescente por energia elétrica, ao mesmo tempo em que deveria atender às exigências da sociedade por um serviço prestado com qualidade, pelo qual se pagassem tarifas justas.

As competências legais desse ente regulador são definidas na Lei 8.987/95, e na Lei 9.427/96, alterada pela Lei 10.848/04. Destacam-se dentre os incisos $V$ e VI do artigo 29, da Lei 8.987/95, com os quais fica a ANEEL autorizada a:
V - homologar reajustes e proceder à revisão das tarifas na forma desta Lei, das normas pertinentes e do contrato;

$\mathrm{VI}$ - cumprir e fazer cumprir as disposições regulamentares do serviço e as cláusulas contratuais da concessão.

A estrutura organizacional da Agência está estabelecida no Decreto 2.335, de 6 de outubro de 1997, o qual aprova a estrutura básica do ente, constituído de: Diretoria, Procuradoria-Geral e Superintendências de Processos Organizacionais (SPO), ficando a cargo do regimento interno dispor sobre a estruturação, atribuições e vinculação das unidades organizacionais.

A Diretoria Colegiada é composta pelo diretorgeral e quatro diretores indicados e pelo Presidente da República, o qual, após aprovação pelo Senado Federal, faz a nomeação dos indicados. Compete aos membros da diretoria analisar, discutir e decidir sobre assuntos internos e externos à Agência. Os mandatos dos diretores são de quatro anos, não coincidentes. A atuação da diretoria é em regime de colegiado, isto é, as decisões são tomadas pelo conjunto dos seus membros.

No contexto deste artigo, cabe destacar, dentre as 23 SPO da Agência, a Superintendência de Regulação Econômica (SRE) a qual tem por competência a execução das atividades relacionadas ao processo de estabelecimento dos valores iniciais, reajustes e revisões de tarifas de energia elétrica. Salienta-se que, na realização dos trabalhos de revisão tarifária periódica, a SRE tem por fontes de informação - Sistema de Acompanhamento de Mercado para Regulação (SAMR), a empresa objeto da revisão tarifária e outras unidades organizacionais da ANEEL.

Reconhecendo a relação de acesso assimétrico à informação, a Agência adotou mecanismos de minimização da assimetria de informação no procedimento de revisão tarifária, conforme ressaltado anteriormente. Dentre tais mecanismos, estão as audiências e as consultas públicas, previstas nas normas de criação, constituição e organização da Agência.

A audiência pública pode ocorrer por sessões ao vivo ou por intercâmbio documental. Antecede o ato administrativo ou o encaminhamento de anteprojeto de lei formulado pela ANEEL, que tenha por consequência afetação de direitos dos agentes do setor 
elétrico e dos consumidores. Com ela objetiva-se, nos dizeres do artigo 21 do Decreto 2.335/97, incisos I a IV:

\author{
i) recolher subsídios e informações para o pro- \\ cesso decisório da ANEEL; \\ ii) propiciar aos agentes e consumidores a pos- \\ sibilidade de encaminhamento de seus pleitos, \\ opiniões e sugestões; \\ iii) identificar, da forma mais ampla possível, \\ todos os aspectos relevantes à matéria objeto \\ da audiência pública; \\ iv) dar publicidade à ação regulatória da ANEEL.
}

Já as consultas públicas têm por finalidade recolher informações e subsídios para o processo decisório envolvendo a emissão de atos administrativos. Com elas buscam-se identificar e ampliar aspectos relevantes que envolvem a matéria em questão.

\section{CONCEITO PRINCIPAL - REVISÃO TARIFÁRIA PERIÓDICA}

Para compreender a importância do procedimento de revisão tarifária, é necessário antes explicitar que é por meio da tarifa que a empresa distribuidora de energia elétrica aufere receita que the permite cumprir o serviço concedido pela União, bem como remunerar os investimentos feitos. Neste trabalho, entenda-se tarifa como o "valor" pago pelo consumidor quando da utilização dos serviços de energia elétrica.

Neste estudo utiliza-se o conceito de Revisão Tarifária Periódica (RTP) nos termos do artigo $2^{\circ}$ da Resolução Normativa nº. 234 de 31/10/2006:

\footnotetext{
[...] revisão ordinária, prevista nos contratos de concessão, a ser realizada considerando-se as alterações na estrutura de custos e de mercado da concessionária, os níveis de tarifas observados em empresas similares no contexto nacional e internacional, os estímulos à eficiência e à modicidade tarifária.
}

A realização da RTP tem por objetivo preservar o equilíbrio econômico-financeiro do contrato e garantir que a tarifa seja justa e que estimule a eficiência e a qualidade do serviço de energia elétrica. São componentes da RTP: o reposicionamento tarifário e o Fator X. Com o reposicionamento tarifário ocorre a redefinição do nível das tarifas de energia elétrica de acordo com o contrato de concessão. É por meio do reposicionamento tarifário que se aufere a parcela da receita suficiente para cobrir os custos operacionais eficientes e a remuneração adequada dos investimentos realizados com prudência.

No reposicionamento tarifário, é utilizado um mecanismo de minimização da assimetria de informação: a empresa de referência, que funciona como uma empresa hipotética ou shadow firm (Piccinini; Pires, 1998), ao simular uma empresa operando em condições de eficiência no cumprimento das atividades e processos inerentes à prestação do serviço público de distribuição de energia elétrica. A vantagem do uso desse mecanismo é que, por meio dele, se simula concorrência que na verdade inexiste, pois, na maioria das vezes, as distribuidoras de energia elétrica constituem monopólios. As desvantagens de seu uso são os elevados dispêndios incorridos na criação do modelo de referência que permita acompanhar e fazer as comparações dos custos e do desempenho da empresa em questão (Piccinini; Pires, 1998).

O outro componente do RTP é o Fator X. A Resolução $n^{\circ}$. 234/2006, no artigo $2^{\circ}$, inciso IX, o conceitua como sendo o "percentual a ser subtraído do Indicador de Variação da Inflação (IVI), quando da execução dos reajustes tarifário anuais entre revisões periódicas, com vistas a compartilhar com os consumidores os ganhos de produtividade estimados para o período."

Outra atividade do procedimento de revisão tarifária envolve a avaliação dos ativos pertencentes à base de remuneração, realizada por empresa credenciada previamente pela ANEEL, a ser contratada pela concessionária distribuidora de energia elétrica. O uso de empresas credenciadas na metodologia de revisão integra o rol de instrumentos utilizados na minimização da relação de assimetria de informação entre a agência reguladora e o agente regulado.

O quarto e último dos instrumentos avaliado neste estudo é o conselho de consumidores. Em uma das fases do procedimento de RTP, a proposta de revisão é discutida com o conselho de consumidores da concessionária distribuidora de energia elétrica. De acordo com a Lei 8.631/1993, artigo 13, o concessionário deverá criar no âmbito de sua área de 
concessão, Conselho de Consumidores, o qual tem caráter consultivo, composto por igual número de representantes das principais classes tarifárias, voltado para orientação, análise e avaliação das questões ligadas ao fornecimento, tarifas e adequação dos serviços prestados ao consumidor final.

\section{REFERENCIAL TEÓRICO REGULAÇÃO E ASSIMETRIA DE INFORMAÇÃO}

A Regulação é consequência do processo de liberalização e privatização de mercados (Genoud, 2003). Falhas nos mercados - externalidades, informação imperfeita, conluio ou ineficiência dos agentes operadores, indivisibilidade do bem/serviço ofertado, monopólios naturais - justificam a necessidade de regulação em determinados setores (Araújo, 1997; Benjó, 1999).

Com a regulação, busca-se:

- atender às aspirações dos atores envolvidos - consumidores, governos e investidores por meio de soluções para conflitos de interesses entre eles;

- elaborar regras claras que possibilitem o desenvolvimento e a eficiência do setor, considerando impactos presentes e futuros de cada decisão tomada;

- atuar com imparcialidade, profissionalismo e conhecimento técnico, livre das pressões de grupos de interesses oriundos de quaisquer das hastes do tripé sobre o qual a regulação se equilibra - consumidores, governos e investidores.

Um dos objetivos da regulação no Brasil é garantir tarifas módicas, possibilitando o acesso, a expansão e a universalização do serviço, bem como assegurar a adequada remuneração do capital investido, de modo a estimular a atratividade e a possibilidade de novos investimentos no setor (Pinto Jr.; Pires, 2001).

Em síntese, de acordo com Benjó (1999, p. 69):

[...] o objetivo da regulação econômica é buscar garantir os retornos sociais desejáveis quando a competição torna-se inexequível. [...] É a criação da 'mão visível', sem a qual não haverá no mercado o equilíbrio natural. Em situações como esta, de mercados imperfeitos, torna-se necessária a intervenção do Estado, por meio da regulação, para garantir que aqueles operem em equilíbrio.

Nesse processo, as agências reguladoras, voltadas para tarefas exclusivas e com pessoal especializado (expertise), devem realizar a coleta, organização e processamento de informações sobre questões da política que está sendo implementada (Genoud, 2003).

$\mathrm{Na}$ presença de expertise, o ente regulador realiza o papel de conselheiro bem-informando políticos e governos na elaboração de melhores políticas. Expertise é também um recurso essencial na realização das competências das agências reguladoras. A eficiência do processo regulatório e a credibilidade do ente regulador dependem da qualidade dos dados de que dispõem e da manutenção de expertise, na presença da qual se fará a análise desses dados.

Há, pelo menos, dois grandes problemas enfrentados pela regulação de mercados: o risco de captura da instituição reguladora e a assimetria de informação entre regulador e regulado (Araújo, 1997; Fiani, 2004).

A captura refere-se à possibilidade de uma empresa ou grupo de empresas operadoras do setor, consumidores ou mesmo o Estado, influenciar na atuação da agência reguladora. Segundo Fiani (2004), a captura pode ser apenas um dos possíveis resultados do processo regulatório, não o único. Em outras situações, o resultado é a definição de regras contra os interesses da indústria. E há ainda a possibilidade de que o resultado da atuação regulatória seja fruto do conflito entre reguladores, como é o caso quando se recorre aos tribunais para a resolução de questões relacionadas à regulação econômica.

A relação entre regulador e regulado é marcada também pela assimetria de informação em benefício do regulado e pela oposição de interesses (Genoud, 2003; Piccinini; Pires, 1998).

Por assimetria da informação entenda-se, no âmbito deste artigo, o fenômeno no qual a parte que detém a informação (regulado) pode adotar comportamento oportunista, manipulando a informação em benefício próprio (Genoud, 2003; Piccinini; Pires, 1998), o que pode prejudicar o processo de formulação estratégica e tomada de decisão do regulador. 
Para evitar que o regulado adote comportamento oportunista no trato da informação que é por ele gerenciada, é desejável que a entidade regulatória faça uso de procedimentos, mecanismos e/ou incentivos (Araújo, 1997) ou imponha penalidades aos regulados que ocultarem e/ou manipularem informações (Shin, 1994). No entanto, o maior controle sobre os agentes acarreta também elevação no custo da regulação (Pinto Jr.; Pires, 2001; Genoud, 2003).

\section{INFORMAÇÃO E ESTRATÉGIA}

Informação é recurso (Tarapanoff, 2002), e como tal deve ser gerenciado a fim de ser útil aos processos organizacionais (McGee; Prusak, 1994). A informação permeia amplamente o processo de formulação e decisão estratégica, impactando nos resultados organizacionais. A informação sem qualidade adequada pode vir a inviabilizar todo o processo de formulação de estratégias, induzindo a erros nas decisões (Reynolds;
Stair, 2002). As consequências dessas situações ensejam prejuízos de várias ordens, financeiros e morais, inclusive.

Outro importante aspecto a ser considerado na relação entre informação e estratégia concerne à quantidade e à qualidade da informação:

[...] a informação aparece tanto de maneira explícita e abundante quanto [de] forma sutil. Por um lado, as empresas são bombardeadas com informação por todos os lados e já foi dito que o conhecimento total existente no mundo dobra a cada cinco anos. Por outro, é patente a escassez de informação correta (McGee; Prusak, 1994, p. 35).

De acordo com Stair e Reynolds (2002), a informação para servir adequadamente aos gerentes e tomadores de decisão, na qualidade de recurso valioso, deve possuir determinadas características, as quais estão relacionadas na Tabela 2 .

Tabela 2. Características da boa informação.

\begin{tabular}{l|l}
\hline Características & Conceitos \\
\hline Precisa & Não contém erro. \\
\hline Completa & Contém todos os fatos importantes. \\
\hline Econômica & Deve ser relativamente econômica para ser viabilizada. \\
\hline Flexível & Que pode ser usada para uma variedade de propósitos. \\
\hline Confiável & Que se conhece o método de coleta e a origem. \\
\hline Relevante & Essencial para o tomador de decisão. \\
\hline Simples & Não excessivamente complexa. \\
\hline Pontual & Obtida quando necessária. \\
\hline Verificável & Que se pode conferir e assegurar de que está correta. \\
\hline Acessível & De fácil acesso aos usuários autorizados. \\
\hline Segura & Cujo acesso só é permitido aos usuários autorizados. \\
\hline
\end{tabular}

Fonte: Adaptado de Reynolds; Stair (2002).

Quanto aos recursos tecnológicos, não convém creditar-lhes a capacidade de resolver o problema do excesso ou escassez de informação, ou de garantir sua 
auxilia o processo de planejamento estratégico, a implementação e o controle da estratégia. Torna-se menos dispendioso o uso da informação na realização de eventuais correções dos desvios indesejados (McGee; Prusak, 1994), bem como mudança de rumos necessária diante de novas contingências e/ou na iminência de uma nova estratégia (Mintzberg; Ahlstrand; Lampel, 2000).

\section{CONHECIMENTO E INFORMAÇÃO}

A relação de informação e conhecimento permeia grande parte dos estudos da Ciência da Informação. Por exemplo, para Farradane (1979) informação é a forma física de representação, ou substituição, do conhecimento ou de um pensamento particular, utilizados na comunicação. Outro conceito é apresentado por Nonaka e Takeuchi (1997, p.63), para os quais informação é o "meio ou material necessário para extrair e construir o conhecimento. Afeta o conhecimento, acrescentando-lhe algo ou o reestruturando." Esses autores também creditam à informação a função de fonte criadora do conhecimento, pois, da interação entre as pessoas, compartilhando informações, constrói-se o conhecimento, que se torna o suporte para julgamento, comportamento e atitudes do ser.

○ conteúdo da informação é resultado da cognição e da avaliação, fruto do conhecimento e do juízo de valor do indivíduo. Ao se considerar a informação como verdadeira e exata, o que ocorre é o processo de interpretação e julgamento baseado na atividade cognitiva e avaliativa do indivíduo. Produtividade e eficiência não são efeitos da informação enquanto registro, mas a consequência da capacidade cognitiva e avaliativa, "a qualidade do conteúdo da informação é determinada não pela expressão linguística, mas pelos processos de cognição e avaliação" (Fogl, 1979, p.6).

A importância da informação relaciona-se à possibilidade que ela oferece de interpretação de eventos ou objetos, pois que, em sua presença, realçam-se significados e evidenciam-se conexões antes despercebidas (Nonaka; Takeuchi, 1997).

Quanto ao conhecimento organizacional, é resultado do conjunto dos conhecimentos individuais, constituindo-se como parte do conhecimento da entidade administrativa. Os conhecimentos tácito e explícito interagem, favorecendo a criação e a expansão do conhecimento por meio da "interação social", ou seja, por meio da conversão do conhecimento (Nonaka; Takeuchi, 1997). Por esse motivo, é importante facilitar o compartilhamento de informações e conhecimento entre empregados mais antigos com os novatos, "conhecimento adquirido por meio da experiência, pela aprendizagem, por acertos e erros, e pela observação de estagiários" (Mclnerney, 2006, p.61).

Compartilhamento de informações é sustentado na confiança entre aqueles que desejam explicitar conhecimento e divulgar experiências. Fatores relacionados à criação de um ambiente de confiança são: comunicação franca e honesta, políticas de pessoal adequadas, encorajamento ao risco e à experimentação (Mclnerney, 2006).

\section{TOMADA DE DECISÃO E INFORMAÇÃO}

É por meio do processo de tomada de decisão que se delineiam, no âmbito organizacional, caminhos a serem seguidos, ações a serem implementadas, esforços a serem concentrados e direcionados na busca da realização dos resultados pretendidos.

A informação é o principal insumo deste processo, pois torna possível realizar as etapas de: reconhecimento, análise e decomposição do problema, proposição de alternativas, decisão e implementação do curso de ação escolhido.

estabelecimento de objetivos e metas para uma organização administrativa evidencia um comportamento planejado, assim como a escolha de uma dentre as alternativas disponíveis denota racionalidade (Simon, 1979). Contudo a racionalidade possui limites, visto que, para ser plena, requer conhecimento completo do resultado de cada escolha. $\bigcirc$ que as pessoas possuem, cada uma a seu modo, são partes de conhecimento das possíveis consequências futuras das decisões que no presente tomam. "A racionalidade completa é limitada pela ausência de conhecimento" (Simon, 1979, p.84).

Assim, são subsídios no processo de tomada de decisão, ou seja, de solução de problemas (Tarapanoff, 2002) - o dado, a informação e o conhecimento. A 
dificuldade reside em transformar dado em informação, e esta em conhecimento de forma útil à tarefa de decidir, sem deixar que prevaleçam as preferências individuais (Angeloni, 2003).

A informação e o conhecimento necessários à efetiva tomada de decisão encontram-se por toda organização (Simon, 1979). Cabe ao sistema de comunicação organizacional transmitir informação e conhecimento necessários ao processo decisório. $\bigcirc$ sistema de comunicação também busca o consenso como forma de adequar a conformação de planos individuais, reforçando no ambiente organizacional a lógica do convencimento, em detrimento da imposição e da manipulação (Angeloni, 2003).

Para Simon (1979) apud Pidd (1998), a racionalidade do processo de tomada de decisão é limitada por dois aspectos: busca e satisfação. No primeiro caso, há busca sistemática por opções, em contraposição à teoria clássica da decisão, a qual supõe conhecido, desde o início, o conjunto de opções possíveis. A busca por opções implica maiores custos incorridos. Quanto à satisfação, ressalta-se que o decisor busca por opções que se lhe apresentem como adequadas, ou seja, que não sejam apenas possíveis, mas também aceitáveis. Assim, a busca será satisfeita tão logo se encontre a opção que atenda esse aspecto do ponto de vista do decisor (Pidd, 1998).

\section{GESTÃO DO CONHECIMENTO ESTRATÉGICO}

A Gestão do Conhecimento Estratégico (GCE) é o processo de criação, captura, assimilação e difusão do conhecimento organizacional relacionado às atividades de planejamento, descrição, impacto, previsão, avaliação e geração de estratégias. A GCE favorece ao expent reconhecer "interações fundamentais entre um tipo específico de informação (tecnológica, legal, social, política etc.) e a ação estratégica adotada" (Costa; Miranda, 2005, p.2).

Assim, a GCE é espécie da qual Gestão do Conhecimento (GC) é gênero. Enquanto a GC foca todo o conhecimento importante para o desenvolvimento das atividades organizacionais, a GCE ocupase do conhecimento necessário às formulações e decisões estratégicas.

Para Miranda (2006), o modelo da GCE caracteriza-se por ser formado a partir da integração dos modelos conceitual, matemático e sistema. Outro aspecto é que o modelo considera os seguintes atores: estrategistas e tomadores de decisão, sendo estes últimos classificados, segundo o tempo de atuação nas atividades de planejar e tomar decisões, entre novatos e experientes.

Por fim, vale ressaltar que a GCE considera fatores sistêmicos, por interferirem nos resultados dos processos organizacionais:

- Cognição - fator relacionado ao processo mental, experiência, capacidade de julgamento e outros que determinam o padrão de ação dos estrategistas e dos tomadores de decisão.

- Tecnologia - interfere na infra-estrutura da GCE. Esse fator está associado com Tecnologias da Informação e da Comunicação usadas para apoiar o processo de formulação estratégica e o processo de decisões estratégicas.

- Cultura Organizacional - fator associado a valores e crenças compartilhadas pelos empregados nas organizações.

- Estilo de gestão - relaciona-se com lideranças tomadoras de decisões estratégicas, estrutura do poder organizacional e claras proposições de valores e objetivos.

- Contexto - diz respeito aos assuntos relacionados com o ambiente interno e externo da organização.

Nesse sentido, formular estratégia, na visão de Miranda e Costa (2005), diz respeito à combinação de cinco processos cognitivos: o diagnóstico da situação, a avaliação de opções, a seleção da melhor opção, a decisão e a implantação. Esses processos, por sua vez, ocorrem dentro de uma estrutura organizacional e sofrem influência dos seguintes elementos:

- contexto político;

- divisão de poder interno;

- cultura organizacional; e

- emoções de seus atores.

Os dois principais atores desse processo são os estrategistas e os decisores, cabendo aos primeiros a formulação de opções estratégicas e aos segundos, a decisão pela mais adequada. 
No que diz respeito ao perfil dos formuladores e decisores estratégicos, Miranda (2006) refere-se a dois tipos em especial:

- Experientes: profissionais com considerada experiência em assuntos estratégicos, os quais "tendem a usar mais o conhecimento tácito em seus trabalhos."

- Novatos: profissionais com pouca experiência em assuntos estratégicos, os quais recorrem mais ao uso do conhecimento explícito na realização de suas atribuições.

Importante frisar que, de acordo com Miranda (2006), estrategistas e decisores, experientes e novatos possuem formas distintas de perceber e agir dentro de seus campos de atuação.

\section{PROCEDIMENTO METODOLÓGICO}

A temática do estudo é, sob a perspectiva da gestão do conhecimento estratégico, avaliar os possíveis impactos da assimetria de informação na atuação de estrategistas e decisores, no procedimento de revisão tarifária periódica das distribuidoras de energia elétrica adotado pela ANEEL.

Trata-se de pesquisa do tipo hipotético-dedutiva, ex-post facto, descritiva, documental, de campo, estudo de caso, com coleta e análise de dados quantitativos e qualitativos.

Abordou-se a situação-problema na sequência abaixo:

- Contextualização, descrição e caracterização do procedimento de revisão tarifária como conceito central do estudo;

- Construção de referencial teórico;

- Construção de metodologia de pesquisa;

- Definição do método de coleta de dados e das variáveis;

- Elaboração de questionário para coleta de dados, com aplicação de pré-teste

- Elaboração de roteiro para entrevista e realização de entrevistas;
- Descrição e análise, discussão dos resultados; e

- Conclusões e recomendações/sugestões para estudos futuros.

As variáveis de pesquisa são: procedimento de revisão tarifária, assimetria da informação, Gestão do Conhecimento Estratégico e Fatores Sistêmicos da Gestão do Conhecimento Estratégico.

Os dados foram coletados por meio da aplicação de dois tipos de questionários e da realização de duas entrevistas. Os dois questionários, após uma versão preliminar, foram submetidos a pré-teste no âmbito da ANEEL. Os revisores do questionário no pré-teste não participavam do universo de pesquisa. Os dados coletados foram tabulados e tratados estatisticamente por meio do Microsoft Excel. Como conseqüência, realizou-se descrição e análise com vista a comparar os dados encontrados, confrontando-os entre si e com a literatura referenciada.

A população estudada envolveu a participação de 12 estrategistas, três decisores e a entrevista com um ex-decisor e um ex-estrategista.

\section{DADOS COLETADOS E DISCUSSÃO}

Os dois questionários aplicados foram divididos em três partes, a saber: I) delinear o perfil dos formuladores da proposta de RTP e dos decisores; II) levantar a percepção desses atores em relação à assimetria de informação e ao procedimento de revisão tarifária das distribuidoras de energia elétrica, e III) coletar dados que evidenciassem os fatores sistêmicos da gestão do conhecimento estratégico entre os profissionais novatos e experientes. $\bigcirc$ questionário dedicado a coletar dados junto aos formuladores da proposta de RTP continha 45 questões, as quais foram respondidas individualmente pelo universo de estrategistas da área que promove o RTP no âmbito da ANEEL. Já o aplicado junto aos decisores foi elaborado com 37 questões, respondidas por três dos cinco diretores.

Devido às limitações de espaço físico reservado ao presente trabalho neste periódico, não se 
demonstrarão todos os resultados da coleta de dados, optando-se por destacar os mais relevantes sob a ótica do que é a seguir discutido.

Com relação ao primeiro objetivo específico, a primeira hipótese e as variáveis "procedimento de revisão tarifária" e "assimetria de informação", observou-se que, para 10 de 11 estrategistas e dois de três decisores, o procedimento de revisão tarifária periódica é dependente de informação. Verificou-se também que há inter-relacionamento com outros procedimentos da ANEEL, conforme julgaram sete de 11 estrategistas e dois de três decisores. São realizadas análises das informações, as quais se refletem na proposta de revisão tarifária submetida à apreciação e à decisão. Salienta-se que, com relação à questão apresentada aos estrategistas, um dos respondentes deixou de avaliar duas questões relacionadas a esse tópico.

Na opinião de oito de 12 estrategistas e três de três decisores, a assimetria de informação é um problema que não foi solucionado pela metodologia adotada pela ANEEL. Aqueles acreditam que a assimetria de informação no procedimento de RTP podese revelar por meio de falhas com relação às seguintes características das informações provenientes das distribuidoras de energia elétrica: completude (conforme avaliado por oito de 12), confiabilidade (sete de 12), precisão (seis de 12) e verificabilidade (cinco de 12). Outras foram apontadas em menor proporção: segurança, acesso, pontualidade, simplicidade e economia. Já para os decisores, as falhas com relação à informação estão relacionadas com: confiabilidade (três de três), precisão (dois de três), completude (dois de três), simplicidade (um de três) e verificabilidade (um de três). A situação pode ser agravada, segundo os diretores, porque as informações são excessivas, replicadas e complexas.

De acordo com de oito de 12 estrategistas, o procedimento de RTP possui mecanismos capazes de detectar falhas nas informações provenientes das distribuidoras, de maneira a possibilitar correções. Os decisores discordam entre si sobre a existência de tais mecanismos: enquanto um discorda que o procedimento possui os referidos mecanismos e reconhece o risco de que as propostas encaminhadas resultem de informações inconsistentes, outro opta por assinalar que possíveis falhas não comprometeriam os resultados da revisão. E um terceiro salienta que há tais mecanismos de prevenção às falhas de informação. No entanto foi salientado que se recorre a outros tipos de informação (informais) para complementar a avaliação, quando aquelas constantes no processo são insuficientes para elucidar algum aspecto.

Dos mecanismos utilizados na metodologia de revisão tarifária, observou-se que estrategistas e decisores apontam as consultas e audiências públicas como mecanismos eficazes no combate à assimetria de informação, isto é, três de 12 estrategistas concordam totalmente e cinco de 12 concordam parcialmente, enquanto que três de três decisores concordam totalmente com a afirmação. Além disso, segundo opinião de um dos entrevistados, além dos subsídios recolhidos e que podem ser utilizados no aperfeiçoamento da metodologia, as consultas e audiências públicas permitem a discussão de outras questões também importantes, mas que não se relacionam diretamente à RTP.

Em oposição, não gozam do mesmo grau de confiança as informações provenientes de: empresas credenciadas, conselhos de consumidores e empresas de referência.

Em resumo, verificou-se que o procedimento de revisão tarifária periódica é fortemente dependente da informação, e que algumas das informações provenientes das distribuidoras de energia elétrica são inadequadas ao processo de decisão, por não atenderem requisitos da boa informação e por serem, na opinião de alguns dos decisores, excessivas, replicadas e complexas. Além disso, dos mecanismos adotados direta ou indiretamente com a finalidade de minimizar a assimetria de informação, as consultas e audiências públicas parecem ser as mais eficazes. Os outros três mecanismos - empresas credenciadas, conselhos de consumidores e empresas de referênciaapesar de serem considerados como mecanismos minimizadores da assimetria de informação, carecem de aperfeiçoamento ou substituição. Considera-se que o primeiro objetivo específico foi atingido e a hipótese confirmada.

O segundo objetivo específico e a hipótese a ele associada dizem respeito à sondagem da percepção do problema de assimetria no RTP pelos estrategistas e decisores. As variáveis consideradas são procedimento de revisão tarifária e assimetria de informação.

fato de estrategistas e decisões concordarem que a assimetria de informação não está solucionada 
implica a situação de alerta e de atenção às situações em que possivelmente o problema possa ocorrer, o que facilita o combate ao problema pelo reconhecimento de sua existência. Isso é corroborado pela afirmação de que, para os formuladores da proposta de revisão tarifária periódica e para os diretores, os mecanismos de minimização da assimetria de informação são falhos, à exceção das consultas e audiências públicas, as quais, no entanto, não abarcam todo o espectro de necessidade informacional do procedimento de RTP, cabendo aos demais instrumentos complementar as informações necessárias.

Assim, considerando-se que os mecanismos de combate à assimetria de informação, conforme dados levantados, são ineficazes, ao mesmo tempo em que o rol de informações é considerado demasiado abrangente, questiona-se se as propostas de revisão tarifária periódica têm sido o resultado da análise de informações sem os devidos requisitos de qualidade. Indaga-se também se a tomada de decisão não tem sido a validação de algo inconsistente ou oneroso para os diretores, os quais, embora indiretamente, acabam por confirmar as falhas dos dispositivos, visto que, conforme alegaram, têm necessidade de complementar os dados disponíveis para a tomada de decisão.

Uma vez que foi realizada a avaliação estabelecida nos termos do segundo objetivo específico, julga-se o objetivo atingido, e a hipótese negada.

O terceiro objetivo específico do estudo e a hipótese a ele relacionada procuraram avaliar se a ANEEL considera a influência, nos estrategistas e decisores, dos Fatores Sistêmicos da Gestão do Conhecimento Estratégico. As variáveis consideradas foram: Gestão do Conhecimento Estratégico e Fatores Sistêmicos da Gestão do Conhecimento Estratégico.

A RTP é atividade desenvolvida por servidores do quadro efetivo da ANEEL, totalizando 12 pessoas à época da coleta de dados - os estrategistas. Já o processo de decisão é de competência da diretoria colegiada da ANEEL, composta por servidores de livre nomeação, em número de cinco quando da coleta de dados - os decisores.

Com relação aos estrategistas, observou-se que à época do levantamento dos dados não havia, dentre os estrategistas responsáveis por realizar a RTP, servidores com mais de 10 anos de experiência com o assunto, sendo, portanto, considerados novatos, conforme classifica Miranda e Costa (2005) e Miranda (2006). O domínio dos conceitos de regulação, revisão tarifária e assimetria de informação, parece ter sido favorecido pelas formações acadêmicas dos servidores, conforme dados coletados, com predominância de bacharelados em engenharia (cinco de 12) e economia (quatro de 12), além dos servidores com títulos adquiridos na realização de cursos de pós-graduação. Possivelmente isso também se dê em função da troca de experiências e informações inerentes ao seu processo de trabalho, considerando-se que, na opinião de 12 de 12 estrategistas, há interação no sentido de troca de informações e experiências, o que ocorre por iniciativa do próprio grupo, na opinião de 12 deles, quando por estímulo do Superintendente, conforme entenderam sete de 12.

Partindo-se dos dados levantados, não se pode atribuir a situação de domínio dos conceitos às ações da ANEEL de promoção de cursos e treinamentos, visto que isso não tem ocorrido, de acordo com a coleta de dados, a qual evidencia que 11 de 12 estrategistas não participaram, até aquela época, de cursos/ treinamento com enfoque nos procedimentos de revisão tarifária oferecidos, pagos e financiados pela Agência. Esse fato permite inferir que a ANEEL não tem buscado desenvolver e manter expertise dos estrategistas por meio desse tipo de instrumento. Isso se opõe ao aspecto da expertise como fator fundamental na criação de eficiência e credibilidade do ente regulador, conforme visto em Genoud (2003), mesmo porque ele reconhece na expertise um mecanismo de combate à assimetria de informação.

Dessa situação é possível inferir a existência de dois problemas. O primeiro refere-se ao fato de que, conforme a literatura especializada, a credibilidade do regulador depende da manutenção de especialização com relação aos assuntos do mercado por ela regulado. Trata-se de um setor complexo, estratégico para o desenvolvimento do país, e que necessita de investimento para atender às crescentes demandas da sociedade, tanto no que diz respeito à universalização dos serviços de energia elétrica, como no que se refere à sua qualidade. Para ser eficaz, no entanto, depende-se da atuação de quadros técnicos capazes de atender às exigências e especificidades do contexto, sob pena de comprometer a credibilidade das ações regulatórias e a confiança dos agentes do setor.

Também os entrevistados referem-se à atuação dos senvidores como situação imprescindível ao combate 
da assimetria de informação, por meio da assimilação de conceitos e situações, e à necessidade de desenvolver expertise para que o pessoal, devidamente qualificado, possa não só perceber a assimetria de informação, como combatê-la e simplificar ou aperfeiçoar os regulamentos.

O outro problema é o risco latente de captura do regulador. A captura ocorre pela adoção consciente de comportamentos e decisões em favor de dado ator do mercado, seja ele governo, instituições organizadas ou empresas reguladas. Mas é possível que ela resulte da assimilação inconsciente de ideias e concepções, propiciada pelo contato direto do ente regulador com os regulados, até mesmo por falta de argumentos contrários aos apresentados pela outra parte interessada.

Com relação aos decisores, observou-se que dois são experientes com relação à regulação de mercados, três de três são novatos com relação ao tema revisão tarifária, e dois são novatos em assuntos de tomada de decisão. Chama-se a atenção para o fato de que, apesar de serem considerados novatos em alguns aspectos, já não o são em outros. $\bigcirc$ desnível em termos de tempo atuando com os temas e como decisor pode ser atenuado pela troca de informação e experiência entre eles, já que três de três concordaram totalmente que é um preocupação dos membros da diretoria a troca de informações e experiências, bem como que atuam de forma integrada em clima de confiança e apoio mútuo. Por outro lado, dois de três concordam totalmente que a agência possui na estrutura de direção colegiada espaço que facilite esse comportamento, enquanto um de três concordam parcialmente com essa afirmação.

Outras ponderações sobre a atuação dos diretores e o processo decisório dizem respeito ao uso de informação informal como recurso à necessidade de precisão e consistência das propostas que lhes são encaminhadas, o qual, anteriormente, no primeiro ciclo de revisão tarifária, já ocorria, conforme declarou um dos entrevistados.

Observou-se que a ANEEL tem agido de forma insuficiente e insatisfatória com relação ao suporte tecnológico e aos sistemas de comunicação, por meio dos quais é possível não apenas trocar informações e experiências como também dirimir dúvidas, ou mesmo estabelecer contato mais efetivo com o fito de levantar informações junto às distribuidoras. Destacam-se alguns dos dados coletados, como por exemplo: sete de 12 estrategistas discordam totalmente da afirmação de que os sistemas informatizados disponíveis fornecem todas as informações necessárias à realização de suas atividades, contra quatro de 12 que concordam parcialmente com a afirmação. Com relação à afirmação, três de três diretores concordam parcialmente. As opiniões ficam divididas para os estrategistas na questão relacionada aos sistemas de comunicação, quando seis de 12 discordam de que os sistemas de comunicação são eficazes. Para os decisores, com relação ao contato com os estrategistas e demais envolvidos com a RTP, os sistemas de comunicação não são totalmente eficazes, visto que três de três concordaram parcialmente com a afirmação.

No que diz respeito ao desenvolvimento e manutenção de expertise como preocupação da ANEEL presente em suas ações administrativas, pode-se inferir que há certa inércia por parte do ente regulador. Isso ocorre porque ela não proporciona aos servidores da equipe de RTP cursos e/ou treinamentos na área, conforme visto anteriormente, incorrendo em, pelo menos, quatro situações desfavoráveis à sua atuação como regulador do setor elétrico:

- deixar de atender à necessidade de formação de expertise, como forma de combate à assimetria de informação;

- criar situação favorecedora da captura;

- onerar o processo de tomada de decisão, considerando-se que é provável que haja maior possibilidade de erros na proposta oriunda da equipe de revisão, o que leva os diretores a recorrerem a mais informações a fim de verificar a consistência do que lhes é apresentado;

- arriscar comprometer a credibilidade e a confiança de suas ações.

Observou-se, porém, um aspecto favorável ao desenvolvimento de expertise dentro da Agência, que diz respeito ao clima organizacional, o qual possibilita a troca de experiência e informações. Isso foi evidenciado nas respostas dadas por estrategistas e decisores a algumas questões, como por exemplo: "[...]
111

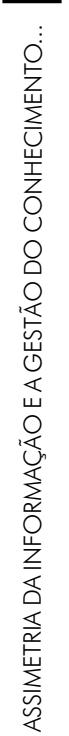

TransInformação, Campinas, 21 (2): 99-116, maio/ago., 2009 
pode-se afirmar que a Agência conta com processos eficazes que possibilitam a troca de informações e de experiências entre [os membros envolvidos na RTP]", ou "[considerando-se o pessoal envolvido na revisão tarifária na SRE] pode-se dizer que há interação entre os membros da equipe, no sentido de trocar informações e experiências?". Para ambas as questões a maioria das respostas foi de concordância.

Relativamente aos fatores sistêmicos da gestão do conhecimento estratégico - cultura organizacional, estilo de gestão e contexto -, observou-se que são aspectos bastante desenvolvidos dentro da agência, sendo amplamente considerados em todo o procedimento de revisão tarifária.

Os decisores preocupam-se com fortalecer, junto aos servidores e aos estrategistas em especial, a necessidade de se atender aos princípios e premissas da regulação de mercados, inclusive os estabelecidos por lei. Essa inferência parte das respostas dadas às questões apresentadas, nos exemplos seguintes, nas quais foi pedido que, considerada a condição de líder e a influência que exerce sobre os subordinados, os decisores julgavam que: "É obrigação legal atuar com transparência." - três de três concordam totalmente; "É um dos objetivos da Agência favorecer o equilíbrio do mercado de energia elétrica, isto é, harmonizar os interesses dos consumidores, das distribuidoras e do governo" - três de três concordam totalmente -; "A universalização dos serviços públicos de distribuição de energia elétrica é princípio na atuação da entidade reguladora" - dois de três concordam totalmente.

Essa percepção é corroborada pela opinião dos estrategistas, na visão dos quais, para as mesmas questões apresentadas, os membros da Diretoria Colegiada fazem questão de enfatizar, na forma como se comportam, os princípios e premissas orientadores das atividades de regulação. Assim, ainda a título de exemplo, para a questão relativa à transparência, 11 de 12 estrategistas concordam totalmente que os decisores fazem questão de evidenciar que tal comportamento constitui obrigação legal. Na questão relativa ao equilíbrio de mercado, 12 de 12 concordam com a afirmação, tendo sete concordado totalmente e cinco, parcialmente. E com relação à universalização dos serviços de energia elétrica, oito de 12 concordaram com a afirmação apresentada.

Em síntese, os dados levantados, as análises feitas e as discussões apresentadas sugerem que a
ANEEL tem considerado apenas parcialmente os fatores sistêmicos da GCE, tendo em vista que, com relação à cultura organizacional, estilos de gestão e contexto, a atuação do ente regulador tem sido percebida fortemente pelos estrategistas e decisores. Contudo, em se tratando de desenvolvimento e manutenção de expertise como instrumento de combate à assimetria de informação, a agência não tem sido pró-ativa, principalmente considerando-se que a formulação da proposta de revisão tarifária tem sido desenvolvida por estrategistas novatos, os quais carecem de melhor entrosamento com os assuntos tratados na RTP. AANEEL tem sido igualmente desatenta com relação aos sistemas de informação e de comunicação, o que finda por onerar os usuários da informação no RTP, o que pode agravar a situação de assimetria de informação existente. Assim, o terceiro objetivo do estudo foi atingido e a hipótese parcialmente confirmada.

Com relação ao quarto e último objetivo específico do estudo, acredita-se que a melhor estratégia de combate à assimetria de informação seria a adoção de postura pró-ativa, ou seja, antecipando-se ao fenômeno e a seus efeitos. Assim, um primeiro passo nesse sentido é o reconhecimento de sua existência e, posteriormente, o desenvolvimento de mecanismos a serem utilizados na metodologia de revisão tarifária, com a finalidade de prevenir que a formulação da proposta de revisão tarifária e a tomada de decisão resultem de informações inadequadas e inconsistentes. Sob a perspectiva dos dados coletados, a ANEEL tem consciência da existência do problema da assimetria de informação, de modo que adota mecanismos na tentativa de minimizar ou neutralizar os seus efeitos no âmbito das atividades desenvolvidas por ela, a exemplo do procedimento de RTP e os instrumentos verificados.

Por outro lado, o procedimento de revisão tarifária é fortemente dependente de informações e está inter-relacionado com outros procedimentos, o que sugere a necessidade de ajustes no sistema regulatório como um todo.

Infere-se que há necessidade de aperfeiçoar os mecanismos adotados no procedimento de RTP como também, e não menos importante, sugere-se que a ANEEL estabeleça ações para desenvolver e manter expertise. Acredita-se que isso seja o cerne de toda a questão investigada, tendo em vista que, pela atuação de estrategistas e decisores, o problema da assimetria informacional possa ser minimizado. Isso porque, em 
situações em que haja melhor compreensão do ambiente regulatório, das forças presentes, dos possíveis ganhos e perdas decorrentes dos ajustes em tarifas, propicie a detecção de situações em que a assimetria de informação possa estar manifestando-se.

Uma questão que pode agravar a situação de relação de acesso assimétrico à informação é o fato de que as atividades de RTP, principalmente no que diz respeito à formulação da proposta de RTP, são desenvolvidas por uma equipe de novatos que, apesar de dominar conceitos e ter consciência de que o problema de assimetria de informação persiste, não têm experiência nos assuntos pertinentes à revisão tarifária periódica. Como consequência, os decisores podem vir a se sentirem inseguros, e procurarem suplementar as informações explicitadas no processo com outras, menos formais, ao procurarem "checar a consistência" do que é apresentado. Contudo, há que se ponderar que o que se chama de insegurança pode ser interpretado, segundo Simon (1979), como um comportamento característico do processo de tomada de decisão, no qual há necessidade de busca e satisfação, visto que na tomada de decisão a racionalidade é limitada. Mas salienta-se também que a atuação de qualquer ente público obriga-se à obediência de princípios da Administração Pública Brasileira, como é o caso dos Princípios da Legalidade e da Eficiência, o que, de alguma maneira, limita a busca e a satisfação.

\section{CONCLUSÕES}

A opção do Estado Brasileiro em adotar a regulação de mercado como uma das formas de garantir que os objetivos da sociedade sejam atingidos, implicou a necessidade de se criar um arcabouço institucional devidamente aparelhado para realizar as tarefas regulatórias. Disso resultou a criação de agências reguladoras com a tarefa de promover o equilíbrio em certos mercados imperfeitos, os quais, após a reforma administrativa da década de 1990, passaram também a ser propriedade da iniciativa privada.

A regulação sofre com dois grandes problemas: o risco de captura e a assimetria de informação. Contudo esses problemas podem e devem ser combatidos por meio de mecanismos eficazes, a fim de garantir que as decisões do regulador reflitam a realidade do mercado que lhe cabe manter em equilíbrio, mesmo porque o desenvolvimento desses mecanismos é, antes de mais nada, uma obrigação, se não imposta por lei ou uma exigência constitucional, um anseio da sociedade.

A ANEEL, como ente regulador do mercado de energia elétrica, enfrenta o problema de assimetria de informação, conforme visto ao longo do trabalho de pesquisa. Por esse motivo, tem-se preocupado em adotar metodologia e desenvolver mecanismos capazes de oferecer resistência ao problema que enfrenta.

Verificou-se que os estrategistas e decisores reconhecem a existência de assimetria de informação no procedimento de RTP. Os decisores, em especial, procuram resguardar-se do problema fazendo uso de expertise e experiência e buscando por informações que complementem aquelas dispostas formal e explicitamente nos processos de revisão. No entanto há que se ponderar essa situação com seu o lado negativo, tendo em vista que essa atitude pode tornar o processo de tomada de decisão demorado e de custo elevado.

Na metodologia de revisão tarifária, há alguns mecanismos que servem à minimização do problema de assimetria de informação. São eles: as empresas credenciadas, os conselhos de consumidores, as empresas de referência e as consultas e audiências públicas. Observou-se que os três primeiros carecem de aperfeiçoamento, a fim de que possam melhor corresponder ao atendimento da função de instrumento de minimização da assimetria de informação. As consultas e audiências públicas, por sua vez, devem ser aperfeiçoadas e incutidas na cultura da sociedade brasileira como meio de levar propostas e discutir questões que, muitas vezes, podem não chegar até o ente regulador por meio dos usuais sistemas de informação e de comunicação.

O estudo indica que a ANEEL não tem considerado amplamente os Fatores Sistêmicos da Gestão do Conhecimento Estratégico no procedimento de revisão tarifária, tendo em vista que não tem sido dada atenção ao fato de que a equipe de revisão tarifária é composta por estrategistas novatos. Acreditase que isso possa ter impacto nos resultados do procedimento de RTP, podendo afetar a credibilidade e confiança depositadas na entidade reguladora. Verificase que a expertise é fator fundamental na compreensão da relação entre dados e informações utilizadas no 
processo de RTP, sem a qual se compromete todo o processo de análise e proposta de revisão. Por outro lado, a proposta de revisão baseada em análises pouco aprofundadas onera os diretores, considerando-se que eles, por experiência, percebem outros níveis de relação entre os dados e informações disponibilizados no processo, sendo necessário buscar suporte às suas considerações em outras instâncias, resultando em retrabalho e demora no processo, ou seja, resultando em ineficiência.

Outros fatores sistêmicos da GCE considerados sugerem que a atuação da agência é fortemente orientada ao atendimento dos princípios gerais da Administração Pública Brasileira. Acredita-se que parte disso é devido à forma como os membros da diretoria se posicionam, de modo que emanam dos líderes as diretrizes que orientam a atuação dos demais colaboradores da agência, no sentido de que as ações desenvolvidas e as decisões tomadas sejam direcionadas para atender as premissas legais da regulação no Brasil.

Destarte, atendendo ao proposto como objetivo geral da pesquisa, avaliou-se que a assimetria de informação impacta na atuação de estrategistas e decisores, o que pode, em algumas situações, levar a questionamentos quanto às proposições de revisão tarifária periódica formuladas, apresentadas e homologadas como decisão da ANEEL, sendo resultado de informações desprovidas de características que as tornem confiáveis para o propósito de auxiliar na formulação estratégica e na tomada de decisão.

Em resumo, observou-se que a ANEEL possui aparato procedimental desenvolvido para a revisão tarifária periódica das distribuidoras de energia elétrica, com uso de mecanismos que funcionam como minimizadores da assimetria de informação. No entanto os mecanismos devem ser aperfeiçoados com vistas a garantir que as informações necessárias à formulação da proposta de revisão tarifária e à tomada de decisão retratem a realidade dos fatos, e que a agência não se torne refém da assimetria de informação com o regulado.

Acredita-se que o ente regulador deva preocuparse em criar condições para que a força de trabalho atuante no procedimento em estudo seja qualificada de modo a favorecer o desenvolvimento e manutenção de expertise como forma de combater a assimetria de informação. Propõe-se que especial atenção seja dada a essa questão, tendo em vista que é por meio da expertise que o agente regulador pode compreender a relação entre informações, permitindo-lhe melhor julgamento e avaliação de situações, nas quais a assimetria da informação está presente. Assim, devidamente preparados, os estrategistas e os decisores estarão aptos a propor melhorias no procedimento e ajustes nas normas.

Ainda nesse sentido, reconhece-se que expertise pode ser ingrediente vital no combate à captura do agente regulador, como também é pressuposto da criação e manutenção da imagem de confiabilidade e credibilidade do ente regulador. A criação dessa imagem junto à sociedade deve ser tarefa da ANEEL, como também das demais agências reguladoras brasileiras, de forma que se possa justificar-lhe a existência e consolidar-lhe como ente sério e de referência na Administração Pública Brasileira.

Ressalta-se, ainda, a importância de a Ciência da Informação focar, em seus estudos, os aspectos da assimetria da informação, considerando outros mecanismos que venham a minimizá-la e aproveitandose dos estudos de GCE para esse intento.

Finalmente, considerando-se que o estudo em tela não esgota questões de relevância para a Ciência da Informação, sugere-se o aprofundamento do tema, discutindo-se, em especial:

- o impacto da expertise e da experiência em processos regulatórios;

- outra possível face da assimetria de informação - a assimetria de informação em benefício do regulador em detrimento do regulado;

- assimetria de informação e o risco de captura - inter-relações entre os principais problemas regulatórios.

- a Gestão do Conhecimento no processo de criação das empresas de referência - o que a experiência e o conhecimento têm contribuído no aperfeiçoamento do modelo de empresas de referência;

- a informação e tomada de decisão - o desenvolvimento de expertise como meio de ampliar a percepção das relações entre dados e informações utilizados nos processos decisórios; 
- assimetria de informação em favor do regulador e em detrimento do regulado - o resultado do procedimento de revisão tarifária visto sob a ótica dos agentes externos à ANEEL;

- a assimetria de informação e os custos para combatê-la - quanto custa saber o que se precisa na regulação de mercados? e

- processo de tomada de decisão no procedimento de revisão tarifária - como os diretores reagem e combatem a assimetria de informação e quais os custos disso para as agências reguladoras.

\section{REFERÊNCIAS}

ANGELONI, M.T. Elementos intervenientes na tomada de decisão. Ciência da Informação, v.32, n. 1, p. 17-22, 2003.

ARAÚJO, J. R.H. Regulação de monopólios e mercados: questões básicas. In: SEMINÁRIO NACIONAL DO NÚCLEO DA ECONOMIA DE INFRA-ESTRUTURA PRONEX, 1., 1997, Rio de Janeiro. Anais... Rio de Janeiro: PRONEX, 1997.

BENJÓ. I. Fundamentos de economia da regulação. Rio de Janeiro: Thex, 1999.

BRASIL. Lei n. 9.427, de 26 de dezembro de 1996: institui a Agência Nacional de Energia Elétrica (ANEEL), disciplina o regime das concessões de serviços públicos de energia elétrica e dá outras providências. Disponível em: <www.planalto.gov.br>. Acesso em: 1 ago. 2006.

BRASIL. Lei n. 9.472, de 16 de julho de 1997: dispõe sobre a organização dos serviços de telecomunicações, a criação e funcionamento de um órgão regulador e outros aspectos institucionais, nos termos da Emenda Constitucional $n^{\circ} 8$, de 1995. 1997a. Disponível em: <www.planalto.gov.br>. Acesso em: 1 fev. 2007

BRASIL. Lei n. 9.478, de 6 de agosto de 1997: dispõe sobre a política energética nacional, as atividades relativas ao monopólio do petróleo, institui o Conselho Nacional de Política Energética e a Agência Nacional do Petróleo e dá outras providências. 1997b. Disponível em: <www.planalto.gov.br>. Acesso em: 1 fev. 2007.

BRASIL. Lei n. 9.782, de 26 de janeiro de 1999. Define o Sistema Nacional de Vigilância Sanitária, cria a Agência Nacional de Vigilância Sanitária, e dá outras providências. Disponível em: <www.planalto.gov.br>. Acesso em: 1 fev. 2007.

BROOKES, B.C. The foundations of information science: part I: philosophical aspects. Journal of Information Science, v. 2, n.6, p.125-133, 1980.

FARRADANE, J. The nature of information. Journal of Information Science, v.1, n. 1, p.13-17, 1979.

FIANI, R. Afinal, a quais interesses serve a regulação? Economia e Sociedade, n.23, p.81-105, 2004.
FOGL, J. Relation of the concepts "Infomation" and "knowledge". International Forum on Information and Documentation, v.4, n. 1, p.21-24, 1979.

GENOUD, C. Regulation as a game: the role of independent regulatory agencies in the regulatory process. In: RISK AND REGULATION RESEARCH STUDENT CONFERENCE, 2003, London. Proceedings... London: London School of Economics And Political Science, 2003.

HERSCOVICl, A. Informação, sistema de preços e regulação: uma análise 'heteredoxa' das instituições. Revista de Economia, v.27, n. 1, p.7-32, 2001.

LE COADIC, Y.F. A ciência da informação. Tradução de Maria Yêda F S de Filgueiras Gomes. 2. ed. rev. e atual. Brasília: Briquet de Lemos, 2004.

McGEE, J.; PRUSAK, L. Gerenciamento estratégico da informação: aumente a competitividade e a eficiência de sua empresa utilizando a informação como uma ferramenta estratégica. Tradução de Astrid Beatriz de Figueiredo. Rio de Janeiro: Campus, 1994.

McINERNEY, C.R. Compartilhamento e gestão do conhecimento: profissionais da informação em um ambiente de confiança mútua. In: TARAPANOFF, K. (Org.). Inteligência, informação e conhecimento em corporações. Brasília : IBICT, UNESCO, 2006. p.57-72.

MINTZBERG, H.; AHLSTRAND, B.; LAMPEL, J. Safári de estratégia: um roteiro pela selva do planejamento estratégico. Tradução de Nivaldo Montingelli Jr. Porto Alegre : Bookman, 2000.

MIRANDA, R.C.R. Important competences of strategists and decision makers in the strategic knowledge management model. In: SULIVAN, H. (Ed.). Creating collaborative advantage through knowledge \& innovation. Hackensack: World Scientific, 2006. p. 205-220.

MIRANDA, R.C.R.; COSTA, S.M.S. Strategic knowledge management: a conceptual framework. In: SULIVAN, H. (Ed.). Knowledge management: nurturing culture, innovation and technology: proceedings of the 2005 International Conference on Knowledge Management. Singapore : World Scientific, 2005. p.417-434. 
NONAKA, I.; TAKEUCHI, H. Criação de conhecimento na empresa: como as empresas japonesas geram a dinâmica da inovação. 7 ed. Rio de Janeiro: Campus, 1997.

PEREIRA, L.C.B. Administração pública gerencial: a reforma de 1995. Brasília: [s.n.], 1999. p.17-62.

PIDD, M. Ciências administrativas: entendendo a visão estratégia. In: PIDD, M. Modelagem empresarial: ferramentas para tomada de decisão. Porto Alegre: Bookman, 1998. Cap.2.

PIMENTA, S.G. Agências reguladoras brasileiras e a questão da assimetria de informação. In: ENCONTRO DE ADMINISTRAÇÃO DA INFORMAÇÃO, 1., 2007, Florianópolis. Anais... Florianópolis: ANPAD, 2007. p.1-16.

PINTO JR, H.Q.; PIRES, M.C.P. Assimetria de informações e problemas regulatórios. In: AGÊNCIA NACIONAL DO PETRÓLEO (Brasil). Regulação. Rio de Janeiro: ANP, 2001 . p. 183-203.

PINTO JR, H.Q.; PIRES, M.C.P. Comportamentos estratégicos e assimetria de informação: problemas para o exercício da regulação. Revista Brasileira de Energia, v.7, n.2, p.89-101, 1999.

PIRES, J.C.L.; PICCININI, M.S. Modelos de regulação tarifária do setor elétrico. Revista do BNDES, n.9, 1998. Disponível em: <http:/ /www.bndes.gov.br/conhecimento/revista/rev907.pdf. > . Acesso: 1 mar. 2007.

ROSSETTI, J.P. Introdução à economia. 12. ed. rev. atual. e ampl. São Paulo : Atlas, 1987.

SHIN. H.S. News Management and the value of firms. The Rand Journal of Economics, v.25, n. 1, p.58-71, 1994.

SIMON, H.A. Comportamento administrativo: estudo dos processos decisórios nas organizações administrativas. Tradução de Aluízio Loureiro Pinto. 3. ed. Rio de Janeiro: FGV, 1979.

STAIR, R.M.; REYNOLDS, G.W. Princípios de sistema de informação. Tradução de Alexandre Melo de Oliveira. 4. ed. Rio de Janeiro: LTC Editora, 2002.

STIGLITZ, J.E.; WALSH, C.E. Introdução à microeconomia. Rio de Janeiro: Campus, 2003.

TARAPANOFF, K. Técnicas para tomada de decisão nos sistemas de informação. Brasília: Thesaurus, 2002.

VASCONCELLOS, M.A.S.; GARCIA, M.E. Fundamentos de economia. São Paulo: Saraiva, 1998. 